\title{
Formulation and evaluation of olanzapine loaded chitosan nanoparticles for nose to brain targeting an in vitro and ex vivo toxicity study
}

\author{
J. Joysa Ruby*, V. P. Pandey \\ Department of Pharmacy, Annamalai University, Annamalai Nagar- 608002, Tamil Nadu, India.
}

\begin{tabular}{|c|c|}
\hline ARTICLE INFO & ABSTRACT \\
\hline Article history: & \multirow{11}{*}{$\begin{array}{l}\text { Olanzapine is an atypical antipsychotic drug shows low bioavailability due to extensive first pass metabolism } \\
\text { and results in numerous side effects due to non targeted delivery. The present study was aimed to prepare and } \\
\text { characterize olanzapine loaded chitosan nanoparticles for nose to brain targeting. The olanzapine loaded } \\
\text { chitosan nanoparticles were prepared by ionic gelation of chitosan with tripolyphosphate anions. The formulated } \\
\text { nanoparticles showed mean particle size, polydispersity index and zeta potential to be } 183.1 \pm 8.42 \mathrm{~nm} \text {, } \\
0.122 \pm 0.08,+52.1 \pm 2.4 \mathrm{mV} \text { respectively. The entrapment efficiency and drug loading was found to be } 72.42 \\
\pm 3.65 \% \text { and } 26.04 \pm 2.12 \text {. In vitro drug release was showed a biphasic release pattern with initial burst release } \\
\text { followed by sustained release of formulated nanoparticles. In vitro toxicity studies were carried out on RPMI } \\
2650 \text { human nasal epithelial cell line by MTT assay. The obtained result shows lower toxicity (high IC } \text { nalue) } \\
\text { of nanoformulation as compared to free drug. Ex vivo histopathological studies were carried out by using } \\
\text { excised goat nasal mucosa and the microscopic structure of nasal mucosa shows no significant harmful effects } \\
\text { of formulated nanoparticles. These results illustrate that olanzapine loaded chitosan nanoparticles is a potential } \\
\text { new delivery system for treatment of depressant when transported via olfactory nasal pathway to the brain. }\end{array}$} \\
\hline Received on: $06 / 08 / 2016$ & \\
\hline on: $26 / 08 / 2016$ & \\
\hline $7 / 09 / 2016$ & \\
\hline Available online: $26 / 09 / 2016$ & \\
\hline Key words: & \\
\hline Olanzapine, Ionic cross & \\
\hline linking method, nose to brain & \\
\hline delivery, chitosan, & \\
\hline nanoparticles. & \\
\hline & \\
\hline
\end{tabular}

\section{INTRODUCTION}

Olanzapine (OLA) is a thioenobenzodiazepine class psychotropic agent used for the treatment of schizophrenia and bipolar disorders (Fig.1.) (Bhana and Perry, 2001).

OLA has poor bioavailability $(40 \%)$, due to hepatic first pass metabolism and low permeability due to efflux by $\mathrm{P}$ glycoprotein. Also OLA is associated with numerous dose related side effects due to non targeted dosage forms (Mattiuz et al., 1997). OLA is available as tablet, an orally-disintegrating tablet, which rapidly dissolves in saliva and as $10 \mathrm{mg}$ vial of intramuscular injection. All above dosage forms show low

\section{* Corresponding Author}

J. Joysa Ruby, Research Scholar, Department of Pharmacy Annamalai university Annamalai Nagar- 608002, Tamil Nadu, India.

Tel.: +918903865499; E-mail : joysaruby2010@gmail.com bioavailability due to extensive first pass metabolism and consequences in numerous side effects due to non targeted delivery system.<smiles>Cc1cc2c(s1)Nc1ccccc1N=C2N1CCN(C)CC1</smiles>

Fig. 1: Chemical structure of olanzapine.

Brain targeting of OLA requires a desirable formulation strategy to overcome its first pass metabolism and restrict the barrier from transport of drugs from systemic circulation into the central nervous system thereby reducing the dose related side effects (Sahni et al., 2011, Haque et al., 2012). 
In the recent years, intranasal drug delivery has attracted substantial interest, since it provides a non-invasive route for delivering drugs directly to the CNS and circumventing the BBB (Illum 2007). Drugs administered to the nasal cavity can travel along the olfactory and trigeminal nerves to reach many regions within the CNS and achieves brain targeting (Wang et al., 2003, Ross et al., 2004, Westin et al., 2005). Hence, drug delivery via the nasal route provides potential route for brain targeting. Although, nasal route of administration has gained considerable interest, the most important limitation factor is rapid mucociliary clearance, which is the cause of a limited contact period allowed for drug absorption through the nasal mucosa (Illum et al., 1987, Mygind and Dahl 1998, Ozsoy 2008). Nanoparticles are one such universal approach to improve the pharmacokinetic profile of poor water soluble, low bioavailable and high toxic drugs (Krishna, 2006). Biodegradable polymeric nanoparticles are of interest as vehicles for extended drug delivery and drug targeting (Jean, 1996). Polymeric drug carrier was considered as a promising solution for this problem. Chitosan is a natural polymer has mucoadhesive properties because of its positive charges at neutral $\mathrm{pH}$, which enable an ionic interaction with the negative charges of sialic acid residues on the mucus (Artursson et al., 1994). The mucoadhesive characteristics of chitosan provide a longer contact period for drug transport through nasal mucosa and prevents the clearance of the formulation via mucociliarly clearance mechanism (Lo pez Leon et al., 2005, Sinha et al., 2004). Therefore, chitosan nanoparticles have been extensively evaluated as a drug delivery system (Hafner et al., 2007, Asane et al., 2008, David et al., 1991). Thus chitosan shown to increase nasal absorption due to its mucoadhesion property and thereby increase membrane permeability (Dyer et al., 2002, Yu SY et al., 2004, AlGhananeem et al., 2010, Al-Ghananeem et al., 2011).

The aim of the present study was to prepare and characterize OLA loaded chitosan nanoparticles and produced sustained release of OLA with in the brain. To our knowledge, this is one of the first reported studies to investigate the nasal toxicity of psychotic drug OLA loaded chitosan nanoparticles by using human nasal epithelial cell lines RPMI 2650 and on excised goat nasal mucosa which benefits in decrease the dose and frequency thereby reducing related side effects with improved therapy.

\section{MATERIALS AND METHODS}

\section{Chemicals and Reagents}

Olanzapine obtained from Hetero Drugs, Hyderabad, chitosan, 400 kD MW (Sigma Aldrich, Mumbai), sodium tripolyphosphate $85 \%$ deacetylated (Sigma Aldrich, Mumbai), acetic acid (S.D. Fine Chemicals).All other chemicals were of analytical grade. Ultra pure water (Milli-Q plus system, Millipore, USA) was used to prepare all stock solutions.

\section{Preparation of olanzapine loaded chitosan nanoparticles}

Olanzapine loaded chitosan nanoparticles were prepared by ionotropic gelation (Calvo et al., 1997) of chitosan with tripolyphosphate (STPP) anions at the different concentration of drug polymer ratio. The chitosan was dissolved in $1 \% \mathrm{v} / \mathrm{v}$ aqueous acetic acid, and the $\mathrm{pH}$ was maintained at 4.8 with $10 \mathrm{~N} \mathrm{NaOH}$. Nanoparticles were obtained upon the addition of STPP aqueous solution $(1 \mathrm{mg} / \mathrm{mL})$ to chitosan solution $(2 \mathrm{mg} / \mathrm{mL})$ under magnetic stirring at $1000 \mathrm{rpm}$ or $2 \mathrm{hrs}$ at room temperature. The association of olanzapine to chitosan was done by incubation for 20 s. The STPP solution was then added into the chitosan and OLA mixture. Then the solution mixture was filtered with membrane filter $(0.45 \mu \mathrm{m})$ to remove the residual particles. The resultant nanoparticles were concentrated by ultracentrifugation at 12,000rpm at $4{ }^{\circ} \mathrm{C}$ for $20 \mathrm{~min}$ (Remi cooling Centrifuge C-24, Mumbai, India). The supernatant was removed and the free drug present in the supernatant was measured by UV-Visible Spectrophotometer (UV -1601, Shimadzu, Japan) at $270 \mathrm{~nm}$. The nanosuspension was lyophilized by using sucrose as a cryoprotectant to form a dried powder of olanzapine loaded chitosan nanoparticles.

\section{Particle size analysis}

The particle size, particle size distribution and polydispersity index were determined by Zetasizer Nano ZS (Malvern Instrument Ltd, Malvern, UK). The sample volume used for the analysis was kept constant $(1 \mathrm{~mL})$ the particles exhibit Brownian motion, which causes the intensity of light to scatter from particles, which is then detected as a change in intensity with suitable optics and a photo multiplier. Each sample was suitably diluted with filtered distilled water to avoid multi-scattering phenomena and placed in a disposable sizing cuvette. The polydispersity index was studied to determine the narrowness of the particle size distribution.

All the data analysis was performed in automatic mode with triplicate measurement within each run. The instrument is well equipped with appropriate software for particle size analysis and PDI.

\section{Zeta potential}

Zeta potential distribution was measured using a zetasizer (Nano ZS, Malvern Instruments, UK). Each sample was suitably diluted five times with filtered, distilled water and placed in a disposable zeta cell. Zeta limits ranged from -200 to $+200 \mathrm{mV}$. The electrophoretic mobility $\left(\mu \mathrm{ms}^{-1}\right)$ was converted to zeta potential by inbuilt software using the Helmholtz-Smoluchowski equation. The average of three measurements of each sample was used to derive the zeta potential.

\section{Scanning electron microscopy}

The surface texture of the optimized nanoparticles was further confirmed by SEM (Zeiss EVO40: Carl Zeiss, Cambridge, UK). Samples were spread over a double -sided conductive tape fixed on to a metallic stud and coated under vacuum with gold in a Blazers SCD020 sputter coater unit (BAL-TEC GmbH, Witten, Germany ) in an argon atmosphere at $50 \mathrm{~mA}$ for 100 seconds. 
Olanzapine loaded nanoparticles- encapsulation efficiency and loading capacity

The encapsulation efficiency (EE) and loading capacity (LC) of olanzapine nanoparticles were calculated as follows, while all the measurements were performed in triplicate and averaged.

$$
\begin{aligned}
& \% \mathrm{EE}=[(\mathrm{A}-\mathrm{B})] / \mathrm{A} * 100 \\
& \% \mathrm{LC}=[(\mathrm{A}-\mathrm{B})] / \mathrm{C} * 100
\end{aligned}
$$

Where $\mathrm{A}$ is the total amount of olanzapine, $\mathrm{B}$ is the free amount of olanzapine and $\mathrm{C}$ is the weight of nanoparticles.

\section{In vitro drug release studies}

The in vitro drug release study was performed using the dialysis bag diffusion technique. The release of OLA from OLANP was performed in methanolic phosphate buffered saline ( $\mathrm{pH} 6.4,30 \% \mathrm{v} / \mathrm{v}$ methanol) to create a perfect sink condition. The nanoparticulate suspension and drug solution each having the same quantity $(5 \mathrm{mg})$ of olanzapine was taken. Nanoparticles equivalent to $5 \mathrm{mg}$ of the drug was placed in a cellulose dialysis bag, (MWCO 12,000g/mole) and to this a little amount of dissolution media was added, which was then sealed at both ends. The dialysis bag was dipped into the receptor compartment containing the dissolution medium, which was stirred continuously at 100rpm maintained at $37^{\circ} \mathrm{C}$. the receptor compartment was closed to prevent evaporation of the dissolution medium. Samples were withdrawn at regular time intervals and the same volume was replaced with fresh medium. The samples were measured by UV Spectrophotometer at $258 \mathrm{~nm}$. All the experiments were performed in triplicate, and the average values were taken.

\section{In vitro cell cytotoxicity using RPMI 2650 cell lines Cell lines and culture media}

RPMI 2650 (Human Nasal Septum carcinoma) cell line was procured from National Centre for Cell Sciences (NCCS), Pune, India. Stock cells were cultured in olanzapine supplemented with $10 \%$ inactivated Fetal Bovine Serum (FBS), penicillin (100 $\mathrm{IU} / \mathrm{mL})$, streptomycin $(100 \mu \mathrm{g} / \mathrm{mL})$ and amphotericin B $(5 \mu \mathrm{g} / \mathrm{mL})$ in a humidified atmosphere of $5 \% \mathrm{CO}_{2}$ at $37^{\circ} \mathrm{C}$ until confluent. The cells were dissociated with a TPVG solution $(0.2 \%$ trypsin, $0.02 \%$ EDTA, $0.05 \%$ glucose in PBS). The stock cultures were grown in $25 \mathrm{~cm}^{2}$ culture flasks and all experiments were carried out in 96 microtitre plates (Tarsons India Pvt. Ltd., Kolkata, India). For cytotoxicity studies, each weighed test drugs were separately dissolved in distilled DMSO and volume was made up with olanzapine supplemented with $2 \%$ inactivated FBS to obtain a stock solution of $1 \mathrm{mg} / \mathrm{ml}$ concentration and sterilized by filtration. Serial two fold dilutions were prepared from this for carrying out cytotoxic studies.

\section{MTT toxicity assay}

The monolayer cell culture was trypsinized and the cell count was adjusted to $1.0 \times 10^{5}$ cells $/ \mathrm{ml}$ using olanzapine containing $10 \%$ FBS. To each well of the 96 well microtitre plate, $0.1 \mathrm{~mL}$ of the diluted cell suspension (approximately 10,000 cells) was added. After $24 \mathrm{~h}$, when a partial monolayer was formed, the supernatant was flicked off, washed the monolayer once with medium and $100 \mu \mathrm{L}$ of different test concentrations of test drugs were added on to the partial monolayer in microtitre plates. The plates were then incubated at $37^{\circ} \mathrm{C}$ for 3 days in $5 \% \mathrm{CO}_{2}$ atmosphere, and microscopic examination was carried out and observations were noted every $24 \mathrm{~h}$ intervals. After $72 \mathrm{~h}$, the drug solutions in the wells were discarded and $50 \mu \mathrm{L}$ of MTT in PBS was added to each well. The plates were gently shaken and incubated for $3 \mathrm{~h}$ at $37^{\circ} \mathrm{C}$ in $5 \% \mathrm{CO}_{2}$ atmosphere. The supernatant was removed and $100 \mu \mathrm{L}$ of propanol was added and the plates were gently shaken to solubilize the formed formazan. The absorbance was measured using a microplate reader at a wavelength of $540 \mathrm{~nm}$. The percentage growth inhibition was calculated using the following formula and concentration of test drug needed to inhibit cell growth by $50 \%\left(\mathrm{CTC}_{50}\right)$ values is generated from the dose-response curves for each cell line (Pavan Kumar Bellamakondi et al., 2014).

$$
\% \text { Growth Inhibition }=\frac{\text { Mean OD of individual test group }}{\text { Mean OD of control group }} \times 100
$$

\section{Ex vivo histopathological Studies on goat nasal mucosa}

Isolated goat nasal mucosa (conchae nasals) was used for the histopathological studies (Jiang et al., 1995). Freshly isolated goat nasal mucosa was obtained from the local slaughterhouse and stored in phosphate buffer solution $\mathrm{pH} 6.4$ and cut into four defined pieces of uniform thickness and diameter. Each piece was treated with PBS, pH 6.4 which will be a negative control, Isopropyl alcohol a nasal mucociliary toxicity agent used as positive control, drug solution at $2 \mathrm{mg} / \mathrm{mL}$, olanzapine loaded nanoformulation $2 \mathrm{mg} / \mathrm{mL}$ respectively. Treatment was done for 2 hours; all the samples were washed and rinsed properly with PBS pH 6.4.

The samples were stored in neutral buffered formalin $10 \%$ and then sectioned, stained with hematoxylin and eosin. The sections were examined on an optical microscope to detect any toxicity by examining the damage to the tissue.

\section{RESULTS AND DISCUSSION}

\section{Preparation and characterization of the nanoparticles}

The olanzapine nanoparticles were prepared by ionic gelation, a gentle technique that involves the mixing of two aqueous solutions at ambient temperature without any harsh chemicals or production stress such as sonication or use of organic solvents (Vander Lubben et al., 2001). Olanzapine nanoparticles were prepared at different concentration of drug, polymer and TPP and it was optimized based on its particle size, polydispersity index and zeta potential and the results were depicted in Table I. At the concentration of chitosan: STPP ratio of 4:1 it was found that the mean particle size, polydispersity index and zeta potential were $183.1 \pm 8.42 \mathrm{~nm}, 0.122 \pm 0.08,+52.1 \pm 2.4 \mathrm{mV}$ respectively for 
optimized formulations (Fig. 2\&3). The NP prepared using optimized parameters had an entrapment efficiency and drug loading of $72.42 \pm 3.65 \%$ and $26.04 \pm 2.12$. High positive values of the zeta potential indicate due to presence of positive charge of amine group of chitosan and it improves the stability of nanoparticles dispersion (Feng and Huang 2001). Nanosuspension particle size and shape was determined by SEM photomicrographs for the optimized olanzapine loaded nanoformulation shown in Fig. 4. The SEM photographs reveals that the particle size were in the range of $170 \mathrm{~nm}$ to $200 \mathrm{~nm}$ with spherical shape morphology.

Table 1: Preparation and characterization of optimized olanzapine nanoformulation.

\begin{tabular}{cccccccc}
\hline $\begin{array}{c}\text { Concentration } \\
\text { of CS mg }\end{array}$ & $\begin{array}{c}\text { Concentration } \\
\text { of STPP mg }\end{array}$ & $\begin{array}{c}\text { Drug: } \\
\text { Polymer }\end{array}$ & Particle Size nm & PDI & $\begin{array}{c}\text { Zeta Potential } \\
\text { mV }\end{array}$ & $\begin{array}{c}\text { Entrapment } \\
\text { Efficiency \% }\end{array}$ & $\begin{array}{c}\text { Loading Capacity } \\
\text { \% }\end{array}$ \\
\hline 40 & 10 & $1: 2$ & $183.1 \pm 8.42$ & $0.122 \pm 0.08$ & $+52.1 \pm 2.4$ & $72.42 \pm 3.65$ & $26.04 \pm 2.12$ \\
\hline
\end{tabular}

All values represent mean \pm SEM, $n=3$.

$\begin{array}{rllll} & & \text { Size }(\text { d.nm): } & \text { \% Intensity: } & \text { St Dev (d.n... } \\ \text { Z-Average (d.nm): } 183.1 & \text { Peak 1: } & 209.2 & 100.0 & 74.05 \\ \text { Pdi: } 0.122 & \text { Peak 2: } & 0.000 & 0.0 & 0.000 \\ \text { Intercept: } 0.937 & \text { Peak 3: } & 0.000 & 0.0 & 0.000 \\ \text { Result quality: Good } & & & & \end{array}$

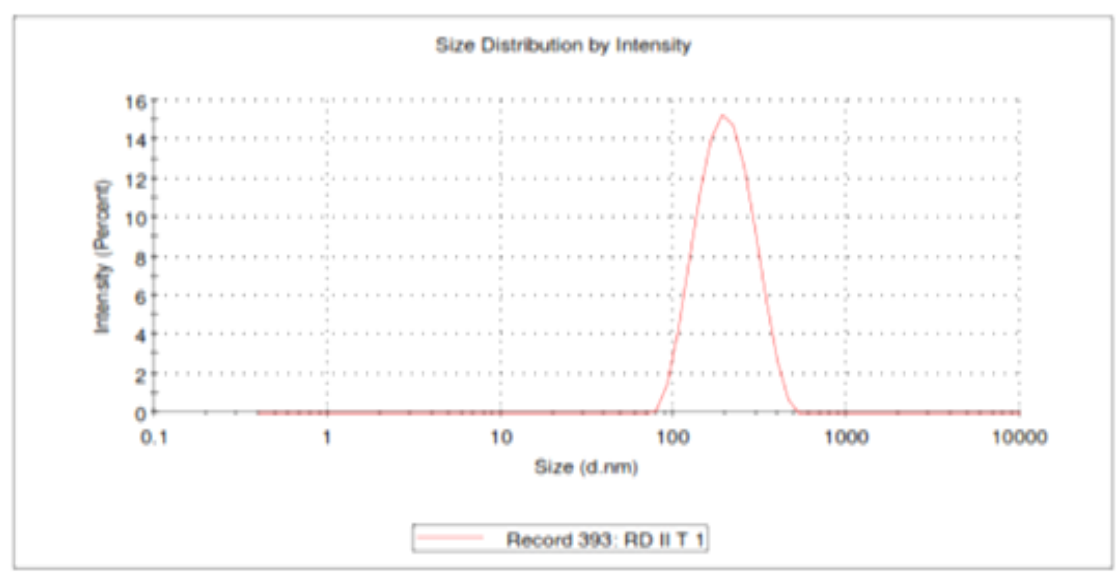

Fig. 2: Particle Size and polydispersity index of OLANP

\begin{tabular}{|c|c|c|c|c|}
\hline & & Mean $(\mathrm{mV})$ & Area $(\%)$ & St Dev (mV) \\
\hline Zeta Potential $(\mathrm{mV}): \mathbf{5 2 . 1}$ & Peak 1: & 52.1 & 100.0 & 4.65 \\
\hline Zeta Deviation $(\mathrm{mV}): 4.65$ & Peak 2: & 0.00 & 0.0 & 0.00 \\
\hline $\begin{array}{r}\text { Conductivity (mS/cm): } 0.526 \\
\text { Result quality : } \text { Good }\end{array}$ & Peak 3: & 0.00 & 0.0 & 0.00 \\
\hline
\end{tabular}

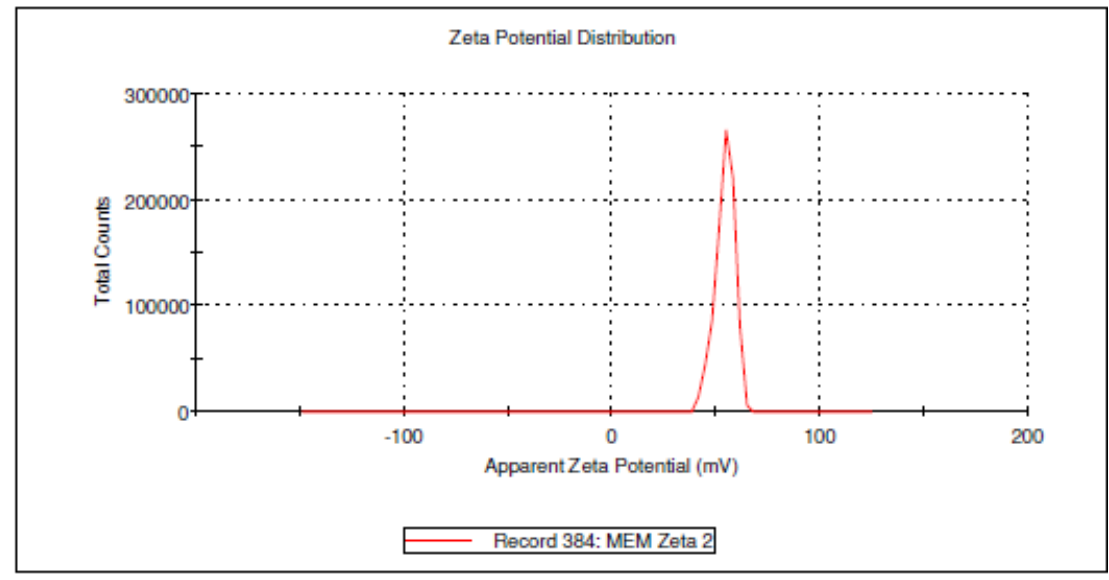

Fig. 3: Zetapotential of OLANP. 


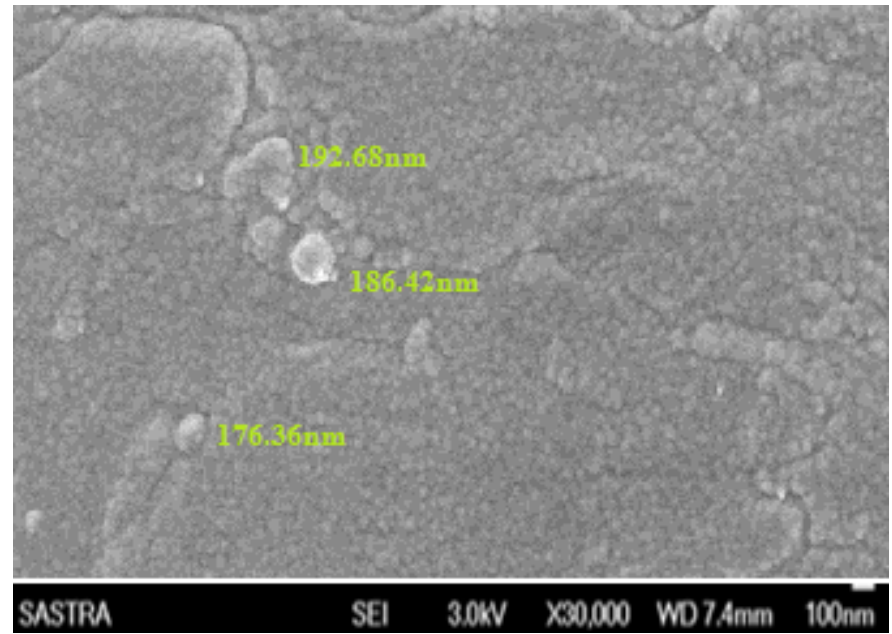

Fig. 4: SEM photograph of olanzapine nanoparticles.

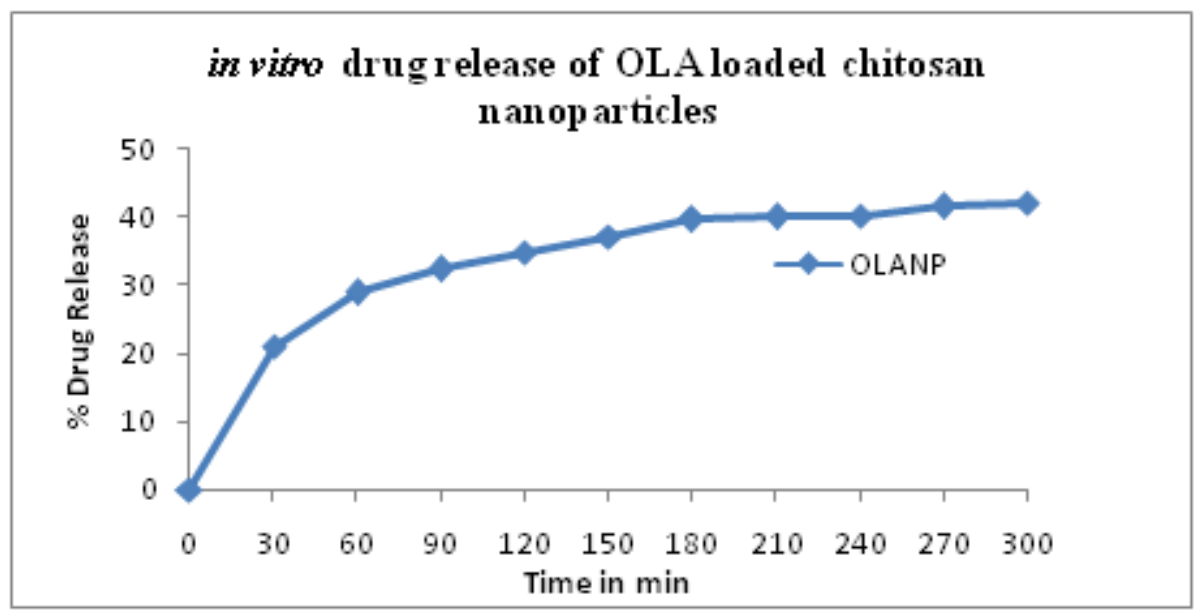

Fig. 5: In vitro drug release of OLA loaded chitosan nanoparticles.

\section{In vitro drug release studies}

The in vitro drug release showed a cumulative percentage release of $21.02 \%$ to $42.23 \%$ for $300 \mathrm{~min}$ for olanzapine nanoparticles suspension. Olanzapine loaded chitosan nanoparticles showed a biphasic release pattern. Initial burst release effect occurred within 30min and the remaining amount of drug was released in a sustained manner for a period of $300 \mathrm{~min}$ (Fig. 5). The initial burst release from nanoparticles is attributed to drug molecules adsorbed on the surface of the nanoparticles which instantaneously dissolve when the particles come in contact with the release medium (Agnihotri et al., 2004).

\section{In vitro cell cytotoxicity using RPMI 2650 cell lines}

The cytotoxicity of pure OLA and OLANP were initially investigated for their antiproliferative activity in human nasal cell line RPMI 2650 based on MTT Assay. As revealed in Fig.6. RPMI 2650 cell lines exposed to OLA and OLANP after $72 \mathrm{hrs}$ of treatment exhibited significant cytotoxicity in a dose dependent manner. The estimated half maximal cytotoxic concentration (CTC) values of OLA and OLANP were greater than $1000 \mu \mathrm{g} / \mathrm{mL}$.
Furthermore, their morphological changes were microscopically examined and the maximum reduction in cell proliferation was observed in OLANP treated cells. Fig.7. indicating that the OLANP shows lesser toxic effects when compared to pure OLA.

\section{Histopathological studies}

The histopathological studies revealed that the condition of goat nasal mucosa after treatment with PBS pH 6.4 a negative control, isopropyl alcohol a positive control, OLA drug solution and OLANP nanoparticles dispersion. The Fig. 8 shows that there is no cell necrosis or cilia detachment from the nasal mucosa was observed after treating with NP dispersion. It indicates that the microscopic structure of nasal mucosa shows no significant harmful effects (Joysa ruby et al., 2015). The nasal mucosa treated with isopropyl alcohol (positive control) shows complete detachment of cilia, loss of epithelial cells and shrinkage of the mucosal layer of epithelial cells. When the nasal mucosa treated with drug solution some cilia got detached from epithelial tissues indicates the toxicity when compared with the negative control treated with PBS treated nasal mucosa. 


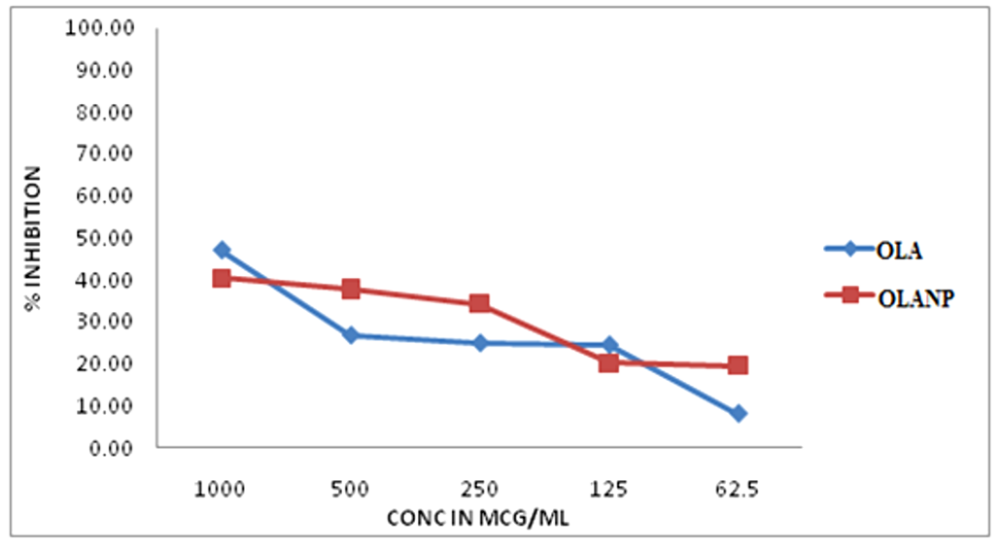

Fig 6: Cytotoxic effect of the OLA and OLANP on RPMI Cell line.

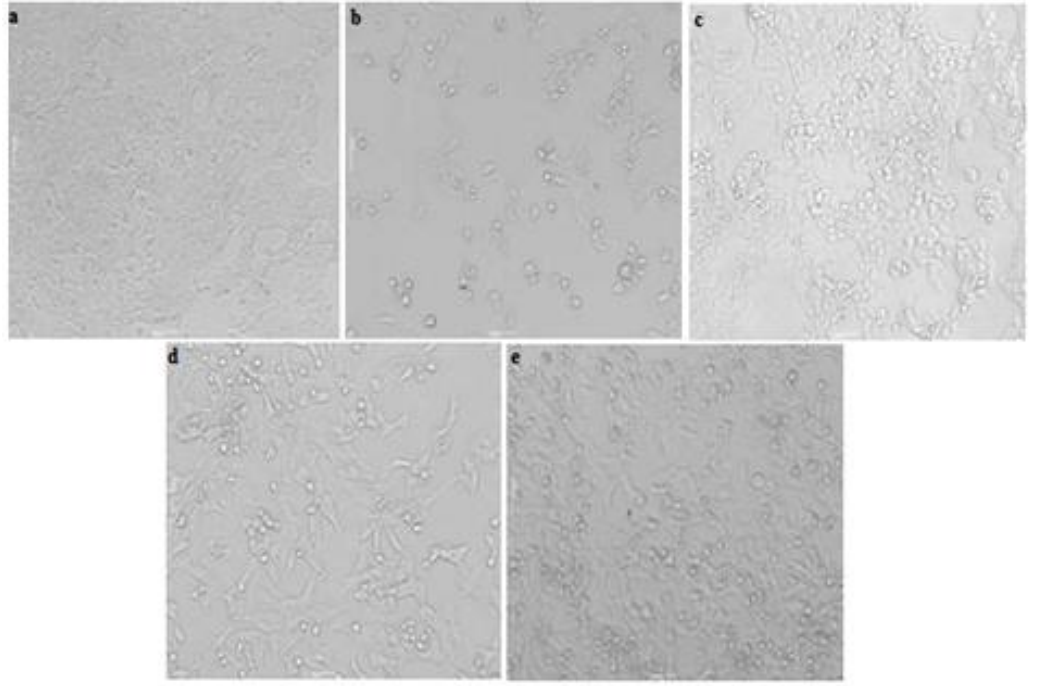

Fig. 7: In vitro cytotoxicity: Microscopic observations of RPMI 2650 cells after 72 hrs of treatment a. Control, b. OLA $1000 \mu \mathrm{g} / \mathrm{mL}$ c. OLA $500 \mu \mathrm{g} / \mathrm{mL}$ d. OLANP $1000 \mu \mathrm{g} / \mathrm{mL} \quad$ e. OLANP $500 \mu \mathrm{g} / \mathrm{mL}$

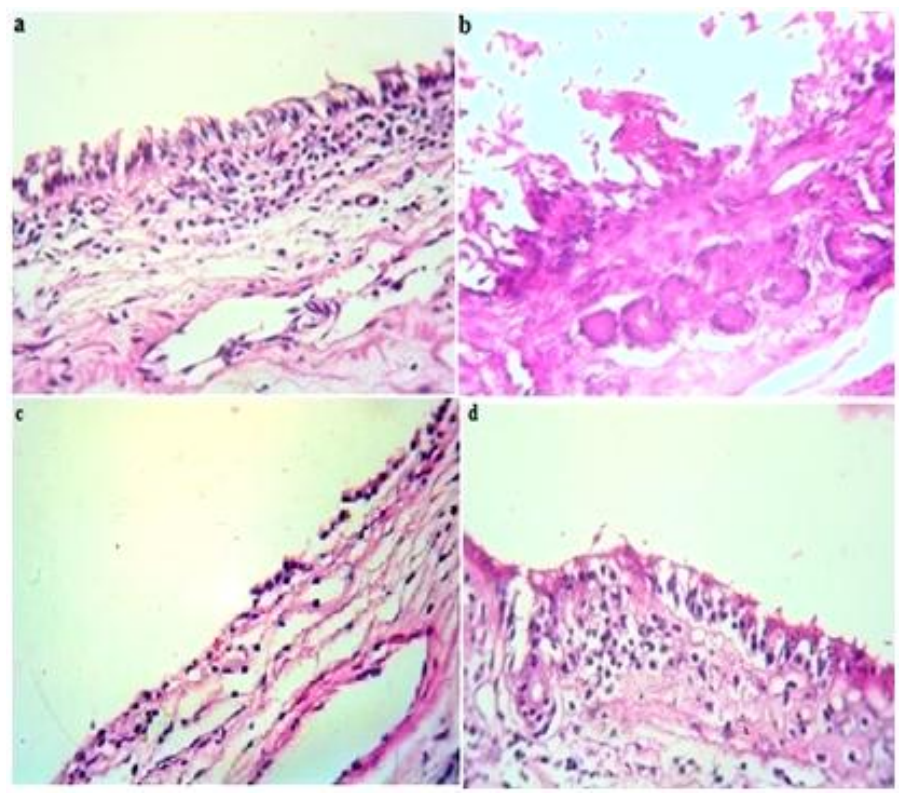

Fig. 8: Histopathalogical images of goat nasal mucosa a. PBS Negative control b.IPA Positive control c.OLA, d. OLANP. 


\section{CONCLUSIONS}

In this study, we formulate OLA loaded chitosan nanoparticles and to investigate feasibility of OLA nasal delivery for brain targeting. OLA-loaded chitosan nanoparticles were prepared by ionic gelation method using sodium tri polyphosphate (STPP) as the crosslinking agent. The optimized formulation were characterized for its particle size, zeta potential, morphological properties, encapsulation efficiency, drug loading, in vitro release study, in vitro toxicity by using RPMI 2650 nasal epithelial cell lines, ex vivo toxicity study by using sheep nasal mucosa. SEM analysis revealed the spherical shape morphology and the average particle size. The in vitro drug release showed a burst release with a sustained release. MTT assay on RPMI 2650 nasal epithelial cell line and ex vivo toxicity on goat nasal mucosa study reveals that there is no toxicity indicating their suitability as carriers for nasal delivery of drugs. These findings suggests that olanzapine loaded chitosan nanoparticles is suitable for nasal delivery for brain targeting.

\section{ACKNOWLEDGMENT}

Authors are thankful to the university grants commission for the financial support to the project under major research project.

\section{Financial support and sponsorship: Nil.}

Conflicts of interest: There are no conflicts of interest.

\section{REFERENCES}

Agnihotri SA, Mallikarjuna NN, Aminabhavi TM. J. Control. Release, 2004; 100: 5-28.

Al-Ghananeem AM, Malkawi AH, Crooks PA. Bioavailability of Delta (9)-tetrahydrocannabinol following intranasal administration of a mucoadhesive gel spray delivery system in conscious rabbits. Drug Dev Ind Pharm, 2011; 37: 329-34.

Al-Ghananeem AM, Saeed H, Florence R, Yokel RA, Malkawi $\mathrm{AH}$. Intranasal drug delivery of didanosine-loaded chitosan nanoparticles for brain targeting; an attractive route against infections caused by aids viruses. J Drug Target, 2010; 18: 381-8.

Artursson P, Lindmark T, Davis SS, Illum L. Effect of chitosan on the permeability of monolayers of intestinal epithelial cells (Caco-2). Pharm Res, 1994; 11: 1358-61.

Asane GS, Nirmal SA, Rasal KB, Naik AA, Mahadik MS, Rao YM. Polymers for mucoadhesive drug delivery system:A current status. Drug Dev Ind Pharm, 2008; 34: 1246-66.

Bhana N, Perry CM. Olanzapine: a review of its use in the treatment of bipolar I disorder. CNS Drugs, 2001; 15: 871-904.

Calvo P, Vila J, Jato L, Alonso MJ. Evaluation of cationic polymer-coated nanocapsules as ocular drug carriers. Int. J. Pharmaceut, 1997; 153: 41-50.

David R, Rohler and Barry R. Gold Spiel Ondansetron: a serotonin receptor antagonist for anti neoplastic chemotherapy induced nausea and vomiting. The annals of pharmacotherapy, 1991;25: 3 .

Dyer AM, Hinchcliffe M, Watts P, Castile J, Jabbal-Gill I, Nankervis R. Nasal delivery of insulin using novel chitosan based formulations: a comparative study in two animal models between simple chitosan formulations and chitosan nanoparticles. Pharm Res., 2002; 19: 998-1008.

Feng S, Huang G. Effects of emulsifiers on paclitaxel (Taxol) from nanospheres of biodegradable polymers. J. Controlled Release, 2001; 71: 53-69.
Hafner A, Filipovic-Grcic J, Voinovich D, Jalsenjak I. Development and in vitro characterization of chitosan-based microspheres for nasal delivery of promethazine. Drug Dev Ind Pharm, 2007; 33: 427-36.

Haque S, Md S, Alam MI, Sahni JK, Ali J, Baboota S. Nanostructure based drug delivery systems for brain targeting. Drug Dev Ind Pharm, 2012; 38: 387-41.

Illum L, Jørgensen H, Bisgaard H, Krogsgaard O, Rossing N. Bioadhesive microspheres as a potential nasal drug delivery system. International Journal of Pharmaceutics, 1987; 39(3): 189-199.

Illum L. Nanoparticulate systems for nasal delivery of drugs: a real improvement over simple systems. J Pharm Sci, 2007; 96: 473-483.

Jean CL. Biodegradable nanoparticles from sustained release formulation to improved site specific drug delivery. Control Release, 1996; 39: 339-35.

Jiang XG, Cui JB, Fang XL, Wei Y, Xi NZ. Toxicity of drugs on nasal mucocilia and the method of its evaluation, Acta Pharmacol Sin. 1995; 30: 848-53.

Joysa Ruby J, Pandey VP, Menaka M. Formulation and evaluation of ondansetron loaded chitosan nanoparticle for nose to brain delivery. Der Pharmacia Lettre, 2015; 7(9):100-108.

Krishna RSM. Nanoparticles: A Novel Colloidal drug delivery system. Indian.J.Educ.Res, 2006; 40: 15-21.

Lo pez Leon T, Carvalho ELS, Seijo B, Ortega-Vinuesa JL, Bastos-Gonzalez D. J. Colloid Interface Sci. 2005; 283(2): 344-351.

Mattiuz E, Franklin R, Gillespie T, Murphy A, Bernstein J, Chiu A. Disposition and metabolism of olanzapine in mice, dogs, and rhesus monkeys. Drug Metab Dispos, 1997; 25(5): 573-83.

Mygind N, Dahl R. Anatomy, physiology and function of the nasal cavities in health and disease. Adv Drug Deliv Rev, 1998; 29: 3-12.

Ozsoy Y. Particulate carriers for nasal administration. Handbook of particulate drug delivery. American Scientific Publisher, 2008; 143-64.

Pavan Kumar Bellamakondi, Ashok Godavarthi, Mohammed Ibrahim, Seetaram Kulkarni, Ramchandra Naik M, Maradam Sunitha. In vitro Cytotoxicity of caralluma species by MTT and Trypan blue dye exclusion. Asian J Pharm Clin Res, 2014; 7(2), 17-19.

Ross TM, Martinez PM, Renner JC, Thorne RG, Hanson LR. Intranasal administration of interferon beta bypasses the blood-brain barrier to target the central nervous system and cervical lymph nodes: a non-invasive treatment strategy for multiple sclerosis. J Neurochem, 2004; 151: 66-77.

Sahni JK, Doggui S, Ali J, Baboota S, Dao L, Ramassamy C. Neurotherapeutic applications of NPs in Alzheimer's disease. J. Control Release, 2011; 152: 208 -231.

Sinha VR, Singla AK, Wadhawan S, Kaushik R, Kumria R, Bansal K. Chitosan microspheres as a potential carrier for drugs. Int $\mathrm{J}$ Pharm, 2004; 274:1-33

Vander Lubben LM, Verhoef JC, Borchard G, Junginger HE. Chitosan and its derivatives in mucosal drug and vaccine delivery. European Journal of Pharmaceutical Sciences, 2001; 14: 201-207.

Wang F, Jiang X, Lu W. Profiles of methotrexate in blood and CSF following intranasal and intravenous administration to rats. Int $\mathrm{J}$ Pharm, 2003; 263: 1-7.

Westin U, Piras E, Jansson B, Bergstro, Dahlin M, Brittebo E. Transfer of morphine along the olfactory pathway to the central nervous system after nasal administration to rodents. Eur J Pharm Sci, 2005; 24: $565-73$.

Yu SY, Zhao Y, Wu FL, Zhang X, Lu WL, Zhang H. Nasal insulin delivery in the chitosan solution: in vitro and in vivo studies. Int $\mathrm{J}$ Pharm, 2004; 281: 11-23.

How to cite this article:

Ruby JJ, Pandey VP. Formulation and evaluation of olanzapine loaded chitosan nanoparticles for nose to brain targeting an in vitro and ex vivo toxicity study. J App Pharm Sci, 2016; 6 (09): 034-040. 